\title{
Processo de pesquisa intervenção formativa por meio do ensino das artes e o desenvolvimento das emoções e sentimentos na escola
}

\author{
Process of formative intervention research through the arts teaching \\ and development of emotions and feelings at school
}

Tatiane da Silva Pires Felix ${ }^{1}$

Irineu Aliprando Tuim Viotto Filho ${ }^{2}$

\begin{abstract}
RESUMO
Este artigo discute e apresenta os principais resultados de nossa tese de doutorado, cujo objetivo volta-se às contribuições de um processo de intervenção formativo, por meio do ensino das artes, para o desenvolvimento das emoções e sentimentos de estudantes em idade escolar. O processo de intervenção contou com 26 encontros semanais, de 90 minutos de duração, com 08 crianças de um segundo ano do ensino fundamental, que participaram de atividades artísticas com música e pintura, com a finalidade de apreensão de aspectos de seu desenvolvimento afetivo-cognitivo. Ao término do processo de intervenção, as crianças apresentaram suas produções artísticas e debateram sobre o aprendizado a respeito das artes e das emoções e sentimentos. Por meio da análise notamos o quanto as intervenções formativas contribuíram para que as crianças se motivassem para a participação em atividades artísticas dentro e fora do contexto escolar e também passaram a falar mais sobre suas emoções e sentimentos. Compreendemos que a intervenção formativa por meio do ensino de atividades artísticas pode contribuir para o desenvolvimento afetivo e cognitivo dos sujeitos participantes do processo.
\end{abstract}

Palavras-chave: Emoção. Sentimento. Arte educação.

\begin{abstract}
This article presents the main results of our doctoral dissertation that aimed to address the contributions of a formative intervention process, through the teaching of arts, to the development of emotions and feelings of students at school age. The formative intervention process featured 26 meetings of approximately 90 minutes, with 08 secondgrade children, who participated in music and painting artistic activities in order to develop their affection and cognition. At the end of the intervention process the children presented their artistic productions and debated about learning arts and the relations with their emotions and feelings. Through the analysis of the process we could notice that the formative intervention process contributed for children to be motivated to participate in artistic activities inside and outside the school context, as well as to talk more about their emotions and feelings. Ultimately, we understand that the formative intervention through the teaching of artistic activities contributed to the affective and cognitive development of the subjects who participated in the process.
\end{abstract}

Keywords: Emotion. Feeling. Artistic education.

\footnotetext{
${ }^{1}$ Professora doutora em Educação, coordenadora pedagógica da rede pública do Estado de Mato Grosso. Seduc-MT, Brasil. E-mail: tatianefelix2@gmail.com.

2 Professor doutor do Programa de Pós Graduação em Educação da Universidade Estadual Paulista, campus de Presidente Prudente, Brasil. E-mail: tuimviotto@gmail.com.
} 


\section{Introdução}

A problematização do tema abordado neste artigo é resultado das discussões da tese de doutorado da primeira autora (FELIX, 2018), que teve sua gênese nos resultados e descobertas em sua dissertação de mestrado, quando nos baseamos na teoria histórico-cultural para compreender o processo de timidez-intimidação no meio escolar.

Torna-se importante esclarecer que, ao longo do desenvolvimento da dissertação de mestrado da primeira autora (FELIX, 2013), encontramos elementos teórico-práticos que nos levaram a pensar, discutir e defender um conceito sobre a timidez, a partir da análise das observações da realidade escolar, que nomeamos processo da timidez em uma relação intimidação-timidez, permeada por um sistema afetivo que relaciona, dialeticamente, as emoções do medo e vergonha ao processo de construção da personalidade dos sujeitos, conforme discussão baseada nos resultados da pesquisa. Concluímos, naquela pesquisa, que a timidez e os processos intimidatórios não tinham sua origem nos próprios indivíduos, mas neles se instalavam, como uma forma de reprodução e resultado de diversas relações sociais opressivas, intimidatórias, alienadas e alienantes presentes na sociedade e reproduzidas nas relações sociais escolares.

Considerando a realidade pesquisada na escola, passamos a defender que, mais importante do que tornar aqueles sujeitos tímidos em autônomos e mais "comunicativos", tornar-se-ia imprescindível transformar o meio social intimidador em que os mesmos estavam inseridos, ou seja, a própria escola. Passamos a defender, portanto, a necessidade de construção de novas condições de aprendizagem e desenvolvimento, a partir de um novo modo de relações sociais, que mobilizasse e desenvolvesse emoções, sentimentos e afetos diferenciados na escola, enfatizando o processo de superação da opressão e alienação, na busca da efetiva humanização dos sujeitos presentes e participantes da escola.

Ao longo de nossa tese de doutorado, enfatizamos a importância do ensino escolar para o desenvolvimento das funções psicológicas, destacando as emoções e sentimentos, embora reconhecendo, conforme orienta Martins (2013), a partir do referencial da teoria histórico-cultural, que os processos psíquicos (funções), não podem ser compreendidos apartados entre si, mas internamente relacionados e 
como parte integrante do sistema psíquico humano. Outra questão importante para a compreensão dos processos psíquicos como as emoções e sentimentos, é que se desenvolvem e se reestruturam a partir de processos de ensino desenvolvidos no interior da educação escolar.

Compreendemos a relação entre afeto e cognição não como dicotomia, mas sim como processos que se relacionam dialeticamente, sendo este, segundo Martins (2011), o aspecto inicial a ser debatido no sentido de entendermos o desenvolvimento das emoções e sentimentos humanos sob a base do materialismo histórico dialético, tarefa que temos nos proposto a realizar ao discutirmos práticas pedagógicas na escola através das produções artísticas.

Para iniciar este debate torna-se importante superarmos a lógica do "ou é isso, ou aquilo", ao analisarmos os aspectos cognitivos e afetivos dos sujeitos, antes, porém, devemos compreendê-los em unidade cognitivo-afetiva, tal como orienta Martins (2011). Neste sentido, Vigotski (2004) defendeu a compreensão das emoções, sentimentos e afetos como elementos da consciência e personalidade humana, desenvolvidos socialmente e essenciais para pensarmos o ser humano como totalidade psíquica.

Ressaltamos que Vigotski (2004) se dedicou a entender o ser humano em sua complexa totalidade, não dicotomizando as emoções e vivências no complexo processo de formação da consciência e personalidade, sendo que, sobre essa relação, o autor afirma que:

Toda emoção é uma função da personalidade, e isto é justamente o que perde de vista a teoria periférica. Assim, a teoria puramente naturalista das emoções requer, a modo de complemento, uma verdadeira e adequada teoria dos sentimentos humanos (VIGOTSKI, 2004, p. 214, tradução nossa).

Dessa forma, o autor nos esclarece que as emoções servem à personalidade como uma de suas funções, não estando, portanto, apartadas do psiquismo humano. Esta concepção refuta as teorias que compreendem as emoções como processo puramente biológico, inerente ao sujeito, ou como simples reflexo a determinado estímulo ambiental e enfatiza o processo histórico-social de 
constituição do psiquismo no qual as emoções devem ser compreendidas como pertencentes à totalidade psíquica do sujeito.

Fica evidente, em Vigotski (2004), a preocupação em tornar nítida a importância dos elementos sociais na constituição das emoções e sentimentos humanos. $\mathrm{O}$ autor criticou as concepções dualistas e defendeu que as emoções e sentimentos deveriam ser analisados em uma unidade psicofísica, ou seja, há que se as entender como unidade inseparável do psiquismo.

Martins (2011), assim como Toassa (2009), afirmam que a posição de Vigotski frente ao estudo das emoções e sentimentos baseia-se nos pressupostos da teoria espinosana, a qual resgata a concepção de que a razão modifica a ordem, as relações e as conexões das emoções. Nessa direção, o que sentimos por outra pessoa tem a ver com o que pensamos dela, ou seja, relaciona-se com a valoração afetiva que dirigimos ao sujeito.

É importante salientar que, segundo Martins (2011), o enfoque dado por Vigotski (2004) às emoções e sentimentos é o mesmo que o autor dirige aos demais processos psíquicos funcionais, a saber, um enfoque sistêmico em que essas funções psicológicas são reconhecidas na relação com as outras funções no bojo da totalidade psíquica do sujeito.

Sobre os processos funcionais, o autor ressalta que a linguagem tem um importante papel no desenvolvimento das emoções e sentimentos, visto que, para Vigotski (1996), assim como as vivências, os sentimentos passam a ser generalizados através da mediação dos significados das palavras. Antes da generalização proporcionada pela palavra, a criança é afetada por emoções ainda destituídas de significado, ou seja, pode, por exemplo, passar por situações de medo, sem significar o que está sentindo, porém, quando internaliza o significado das palavras que conceituam determinado afeto/emoção, passa a conhecer e generalizar tais emoções/afetos.

Podemos afirmar, portanto, que a partir da generalização proporcionada pela palavra com significado social, a criança compreende o que sente, sendo capaz de dizer se sente medo, tristeza ou alegria. Portanto, para Vigotski (1996), ter conhecimento dos afetos através de processos de internalização de seus significados sociais resulta na produção de novas formações internas que transformam 
qualitativamente nossas funções psíquicas, como as das emoções e sentimentos, e também as demais que forem afetadas pela situação vivenciada.

Vigotski, portanto, não dicotomiza as emoções, assim como as demais funções psíquicas; antes, porém, compreende-as em relação com o pensamento, linguagem, percepção e imaginação, ou seja, o autor insere as emoções no contexto das funções psicológicas que sintetizam a personalidade humana (VIGOTSKI, 1996, 2004, 2009b).

Portanto, para Vigotski (2006), as emoções e sentimentos devem ser consideradas funções integrantes do sistema psicológico humano que se apresentam como elementares e superiores. Justamente por isto o autor não as pensa de maneira formal e dicotômica, pois não sustenta que as emoções tenham um caráter superior à vida afetiva e tampouco sejam meras respostas físicas a estímulos sensoriais, como defendiam muitos filósofos e psicólogos de sua época.

Considerando essa compreensão, assumimos o compromisso de pesquisar as emoções na escola e junto à escola, através da efetivação de uma pesquisa intervenção formativa que valoriza o ensino das artes nesse processo. Para tanto, nos baseamos nos pressupostos de Davidov (1988) acerca do experimento formativo e de Vigotski (1996) e seu método genético-causal, e nos dispusemos a intervir na realidade escolar, compreendendo os sujeitos dela participantes, especialmente os alunos, nesse meio social e em pleno processo de construção e transformação.

Esclarecemos que nossa preocupação não é estudar as emoções e sentimentos como funções psicológicas fossilizadas, mas sim buscar compreendêlas em seu processo de desenvolvimento e enfatizando o ensino das artes nesse movimento. Buscamos, intencionalmente, provocar a transformação das emoções e sentimentos por meio do ensino de artes junto a alunos em idade escolar, pois, segundo Vigotski (2006), este é o momento em que os sujeitos começam a generalizar suas emoções e vivências. Discutiremos adiante a importância das artes, como forma e conteúdo, em um processo educativo intencional para o desenvolvimento das emoções e sentimentos. 


\section{0 ensino da arte e o desenvolvimento das emoções e sentimentos}

A escola tem sido, através de décadas, a instituição de maior responsabilidade em educar, transmitir conhecimentos e formar os seres humanos. Saviani (2011) defende que sua função não é a de transmitir qualquer tipo de conhecimento ou conteúdo por quaisquer meios, mas, sim, trabalhar com os conhecimentos universais e sistematizados pela ciência, filosofia, artes, dentre outros. Nessa direção, a escola deve possibilitar a efetivação de um trabalho educativo que valorize o acesso aos conteúdos clássicos, os quais se perpetuaram ao longo do tempo na história da humanidade.

Esta preocupação com a transmissão dos conhecimentos científicos e artísticos na escola é consoante à de Vigotski (2009a, 2009b), pois, de acordo com este autor, tais conteúdos são responsáveis por reorganizar as funções psíquicas, transformando todo o sistema psíquico em um processo de desenvolvimento da personalidade dos sujeitos.

Ao defender os conhecimentos clássicos e universais como conteúdos imprescindíveis no trabalho educativo, a pedagogia histórico-crítica não se limita a um processo educativo conteudista, verbalista e abstrato; pelo contrário, leva em conta a dialética existente entre forma e conteúdo no processo de ensinoaprendizagem e compreende esses elementos em unidade no trabalho educativo do professor (MARTINS, 2011).

Desta forma, além de enfatizar a importância dos conteúdos clássicos e mais elaborados, também é preocupação da pedagogia histórico-crítica a forma com que estes conteúdos são transmitidos/assimilados na escola. Neste sentido, afirma Saviani (2011) que:

O objeto da educação diz respeito, de um lado, à identificação dos elementos culturais que precisam ser assimilados pelos indivíduos da espécie humana para que eles se tornem humanos e, de outro lado e concomitantemente, à descoberta das formas mais adequadas para atingir esse objetivo (p. 13).

Podemos compreender que para Saviani (2011), um trabalho educativo realizado à luz da pedagogia histórico-crítica precisa selecionar os conteúdos clássicos, bem como as melhores formas de ensiná-los, tendo em vista a construção da consciência filosófica, crítica, coerente e de totalidade junto aos estudantes. Para 
o autor, a relevância dos conteúdos representa o dado nuclear da educação escolar, vez que, na ausência de conteúdos significativos, a aprendizagem esvazia-se, transformando-se no arremedo daquilo que de fato deveria ser.

Também é preocupação da pedagogia histórico-crítica que seja levado em consideração a quem se destina o ato educativo. Assim, forma-se o que Martins (2011) chama de tríade forma-conteúdo-destinatário, onde cada um destes elementos precisam estar em relação com os demais, para que, de fato, possa ser realizado um trabalho educativo significativo e de totalidade.

Pensando nestes aspectos defendidos pela pedagogia histórico-crítica e na necessidade de desenvolver as emoções e sentimentos enquanto funções psicológicas essenciais do psiquismo e da personalidade humana, questionamo-nos acerca de quais seriam os conteúdos clássicos que, ao serem ensinados, poderiam promover um maior desenvolvimento destas funções; e as formas, os meios, a serem utilizados no intuito de alcançar o amplo desenvolvimento afetivo dos estudantes por meio da arte.

Com Vigotski (2001), admitimos que a arte deve ser considerada objeto essencial para o desenvolvimento das emoções e sentimentos, pelo fato de os objetos artístico-culturais integrarem dialeticamente forma e conteúdo, possibilitando vivências estéticas significativas para o desenvolvimento das emoções. Segundo o autor "a arte sistematiza um campo inteiramente específico do psiquismo do homem social - precisamente o campo de seu sentimento" (idem, p. 12).

A afirmação acima nos remete à importância das artes no ensino de formas e conteúdos que desenvolvam, sistematizem e reelaborem os sentimentos e emoções humanas. Diante dessa compreensão, podemos afirmar que os estudantes, ao vivenciarem determinadas manifestações artísticas, poderão ter contato com o conteúdo artístico de forma significativa, desde que sejam afetados pela vivência afetivo-emocional, cognitiva e social junto a esses objetos na escola.

Vigotski (2001) também nos dá motivos para defender as manifestações artísticas como instrumento e conteúdo pedagógico das emoções, quando afirma que a arte transforma os sentimentos de quem a vivencia ao sustentar que:

A verdadeira natureza da arte sempre implica algo que transforma, que supera o sentimento comum, e aquele medo, aquela mesma dor, 
aquela mesma inquietação, quando suscitadas pela arte, implicam o algo a mais, acima daquilo que nelas está contido. $\mathrm{E}$ este algo supera esses sentimentos, transforma a sua água em vinho (p. 307).

Assim como a própria arte é manifestação da transformação dos sentimentos e emoções do artista que a produziu, podemos, na escola, "transformar a água em vinho" quando trabalhamos as emoções e sentimentos dos estudantes durante um trabalho pedagógico intencional que possibilita o acesso a obras artísticas clássicas que carregam a genericidade humana.

Ainda neste sentido, para Vigotski (2001, p. 315), "a arte é o social em nós", ou seja, o aspecto social sempre se encontra presente nas obras de arte, isto porque a obra de arte tem um caráter social e histórico, é objetivada em determinado tempo histórico e carrega as vicissitudes dessa história. Duarte (2010) nos explicita que, para Vigotski, a arte é a técnica dos sentimentos, pois constrói uma existência social objetiva das emoções e sentimentos humanos, possibilitando que os demais sujeitos se apropriem desses sentimentos como algo já objetivado em determinada obra de arte. Além de objetivar os sentimentos, a obra de arte supera os elementos da cotidianidade e do imediatismo, pois, reelabora artisticamente os conteúdos da realidade objetiva.

Portanto, por conter em suas formas e conteúdos os conhecimentos relacionados com a história da humanidade, a obra de arte carrega, em si, significados históricos e axiológicos que são transmitidos aos indivíduos, conforme afirma Duarte (2010). Ainda neste sentido, segundo Lukács (1978), os conhecimentos/conteúdos advindos da ciência e a criação artística são elementos da universalidade, ou seja, do gênero humano, e se diferenciam dos conhecimentos de senso comum, da cotidianidade. Pois, para Lukács (1978):

$\mathrm{O}$ conhecimento ligado à prática cotidiana se fixa em qualquer ponta, a depender de suas tarefas concretas e práticas. O conhecimento científico ou a criação artística (bem como a recepção estética da realidade, como na experiência do belo natural) se diferenciam no curso do longo desenvolvimento da humanidade, tanto nos limites extremos como nas fases intermediárias. Sem este processo, jamais se teria concretizado a verdadeira especialização destes campos, a sua superioridade em face da práxis imediata da vida cotidiana, da qual ambos paulatinamente surgiram (p. 159160). 
Para o autor, a base das obras de arte está na vida e na realidade dos homens e, neste sentido, Lukács (1978) nos faz refletir que estes conteúdos contidos na arte são históricos, pois discutem questões referentes a situações oriundas da realidade da época em que foram criados. Para o autor:

Toda obra de valor discute intensamente a totalidade dos grandes problemas de sua época: tão-somente nos períodos da decadência estas questões são evitadas, o que se manifesta, nas obras, em parte como carência de real universalidade, em parte como enunciação nua de universalidade não superadas artisticamente (falsas e distorcidas como conteúdo). (LUKÁCS,1978, p. 163)

A partir destes pressupostos, defendemos que os conteúdos advindos das artes, quando trabalhados em um processo educativo humanizador, podem contribuir para a compreensão da realidade social de diversas épocas, os valores sociais e éticos da humanidade, bem como para com a apropriação de vivências e de sentimentos e emoções humanas essenciais para o processo de humanização dos sujeitos na escola.

É nesse sentido que assumimos as artes como forma e conteúdo fundamentais para o desenvolvimento das emoções e sentimentos na escola, e por este motivo, em nossa pesquisa intervenção formativa, definimos nosso objeto de pesquisa como a relação entre a organização do ensino das artes e o desenvolvimento das emoções e sentimentos de crianças em idade escolar.

No subitem abaixo, adentraremos na organização de nossa intervenção formativa educativa e apresentaremos alguns dos principais resultados de nossa pesquisa.

\section{Pesquisa-intervenção formativa através do ensino das artes}

Nosso processo de pesquisa-intervenção formativa foi viabilizado pela pesquisadora e orientador, com o apoio dos demais membros do GEIPEE-thc, por meio da organização e efetivação do ensino da arte, a fim de enfatizar a importância do trabalho educativo intencional do professor para o desenvolvimento dos processos psicológicos superiores na escola, com ênfase nas emoções e sentimentos. 
Segundo Viotto Filho (2018), a pesquisa-intervenção-formativa não se limita à proposições pontuais de transformação da realidade, como a pesquisa-ação, mas avança e configura-se como um processo grupal de pesquisa, o qual deve ser construído coletivamente e a longo prazo. Para o autor, quando realizado na escola, deve considerar as relações sociais no seu movimento contraditório e efetivado por múltiplas determinações.

A finalidade principal da pesquisa-intervenção formativa é transformar as relações sociais no interior da escola desde a sua estrutura e dinâmica, como apregoa o materialismo histórico dialético. A finalidade de um trabalho de intervenção de natureza educativa é "investigar e compreender a realidade escolar por dentro da própria escola, a fim de transformar as relações sociais e o trabalho educativo nela realizado, com vistas à transformação humana e social" (VIOTTO FILHO, 2018, p.33).

Esclarecemos que uma pesquisa intervenção formativa supera a lógica formal positivista e assume a lógica dialética na compreensão do movimento da realidade, procurando desvendá-la nas suas múltiplas determinações. Este pressuposto salienta a importância da realização de uma pesquisa de caráter interventivo e educativo na escola, tendo em vista que a lógica dialética, ao apreender os fenômenos como síntese de muitas determinações, reconhece-os na sua historicidade, ou seja, no seu movimento histórico e contraditório, o que possibilita a transformação da realidade.

Portanto, em nossa pesquisa, não buscamos identificar meramente os fenômenos para descrever a realidade escolar, muito menos para somente identificar os seus problemas. Procuramos, por outro lado, pesquisar como o ensino das artes deve se efetivar de forma significativa na vida dos estudantes e, para isso, utilizamo-nos de um meio especial de ensino ludo-pedagógico, com objetivo de defender novas e melhores condições de trabalho para todos os professores na escola, sobretudo para aqueles que se comprometem com o real aprendizado e desenvolvimento de seus estudantes numa direção humanizadora. Para tanto, nos baseamos nos pressupostos de Davidov (1988 p. 196, tradução nossa) acerca do experimento formativo para pensar e realizar nosso processo de intervenção formativa. Segundo o autor: 
Para o método do experimento formativo é característica a intervenção ativa do investigador nos processos psíquicos que ele estuda. Com isso, se diferencia essencialmente do experimento de constatação, que põe em manifesto somente o estado já formado e presente de uma ou outra estrutura psíquica. A realização do experimento formativo pressupõe a projeção e modelação do conteúdo das neoestruturas psíquicas a constituir, dos meios psicopedagógicos e das vias de sua formação. Na investigação dos caminhos para realizar este projeto (modelo), no processo do trabalho educativo cognoscitivo com as crianças, pode-se estudar simultaneamente as condições e as leis de origem, de gênese da correspondente neoformação psíquica. Ao nosso juízo, se pode chamar o experimento formativo de experimento genético modelador, que forma a unidade entre a investigação do desenvolvimento psíquico das crianças e sua educação e ensino.

Como mencionado acima, Davidov (1988) afirma que para a compreensão de determinada realidade no experimento formativo, é necessário que o pesquisador intervenha de forma ativa nesta realidade. Em nossa tese, tivemos por objetivo compreender as implicações e relações de nosso processo interventivo de ensino das artes com o desenvolvimento das emoções e sentimentos dos estudantes sujeitos da pesquisa. Assim, trabalhamos com uma relação entre dois eixos, o da organização e efetivação da atividade de ensino e o eixo do desenvolvimento das crianças participantes da pesquisa, com foco nas funções psíquicas das emoções e sentimentos.

Como afirmamos acima, organizamos um meio experimental especial no interior da escola para a realização da intervenção formativa, em que 08 crianças de um segundo ano do ensino fundamental foram sujeitos participantes em 26 encontros de, em média, 90 minutos de duração. Importante salientar, também, que todos os encontros foram filmados e posteriormente transcritos na íntegra. Para a efetivação desse trabalho, utilizamos diversos espaços da escola (sala de aula, sala de leitura, pátio, espaço aberto) e sempre contando com, no mínimo, dois membros do GEIPEE-thc como apoio para a realização das atividades. Optamos pelos alunos do segundo ano, pelo fato de se encontrarem em uma etapa de suas vidas que Vigotski (1996) denomina de período de crise da idade escolar (crise dos sete anos), ou seja, período em que se encontram entre duas etapas consideradas estáveis. Podemos compreender que a infância e a adolescência, por exemplo, são 
consideradas como estágios estáveis, no entanto, a passagem da infância para a adolescência torna-se um período um tanto quanto conturbado e, portanto, chamado por Vigotski (2006) como período de crise.

Para Vigotski (1996), os períodos de crises acontecem a partir da reestruturação das vivências interiores, que foram a princípio vivências concretas, exteriores e que se encontram internalizadas no psiquismo dos sujeitos. Estas reestruturações geram novas necessidades e motivos sociais para a criança agir. Segundo o autor, as crises que marcam a passagem de uma idade estável para a outra acabam por possibilitar que a criança desenvolva novas formações psíquicas que, por sua vez, farão parte do processo de desenvolvimento de sua personalidade. Estas formações, que acabaram de se estruturar, servirão como indicativo fundamental para se compreender o desenvolvimento da criança.

Esta generalização das vivências ajudará as crianças a ter o que Vigotski (1996, p. 379) chama de "orientação consciente" de suas emoções, afetos e características da personalidade, tal como estar contente ou descontente, sentir-se boa ou má, dentre outras orientações acerca de si mesma. Podemos compreender, segundo Vigotski (2006), que nesta relação de novas vivências na escola, de apropriação de conceitos e de desenvolvimento do pensamento, surgem novos enfrentamentos para a criança, e ao mesmo tempo, ela começa a generalizar as vivências de si e seus afetos.

Desta forma, o critério para a escolha dos sujeitos e a criação do grupo de participantes da pesquisa foi organizado por meio de conversas com os pais, professores e gestores da escola sobre quais estudantes teriam maior necessidades de desenvolvimento afetivo-cognitivo, como por exemplo aqueles que tinham dificuldades em se relacionarem com os demais ou que tinham atitudes violentas com os colegas de sala, chegando assim aos 08 sujeitos que ganharam um nome fictício de artistas, a saber: Frida, Cecília, Anita, Tarsila, Clarice, Candido, Leonardo e Vincent.

O processo de intervenção ocorreu inteiramente no interior da escola e contando com a participação de todos os sujeitos convidados; no entanto, para efeito de análise dos dados coletados, escolhemos 04 sujeitos que tiveram participação efetiva ao longo dos encontros: Frida, Tarsila, Cecília e Vincent. 
O processo interventivo formativo contou com 3 blocos temáticos e 4 etapas. Os blocos temáticos foram: Emoções e sentimentos, Artes (música) e Artes (pintura). As etapas do processo interventivo foram: verificação dos conhecimentos já apropriados de cada bloco temático, apropriação (por meio da internalização dos significados sociais) de alguns dos clássicos das artes (música e pintura), apropriação de algumas das principais técnicas das artes (música e pintura) e produção artística de um quadro e a composição coletiva de uma música.

No sentido de categorizar os relatos advindos de nossa observação e da transcrição das filmagens do processo interventivo formativo, criamos episódios de ensino (categoria que engendra temática de ensino com os dados da pesquisa) por meio do cruzamento de dados advindos das temáticas e das etapas do processo de intervenção (NASCIMENTO, 2011, 2014).

Para garantir o movimento e entendimento histórico do desenvolvimento das crianças, seguimos a ordem cronológica em que se efetivaram estes momentos, cruzando as 04 etapas do processo de intervenção e os 03 blocos temáticos dos encontros, como pode ser observado na Tabela 1. Contamos também com um episódio introdutório e um episódio de avaliação dos encontros, totalizando 10 episódios de ensino. A análise dos dados se efetivou conforme a categorização dos encontros nos 10 episódios, levando em conta suas temáticas, como mencionamos no subitem anterior. 
Tabela 1: Categorização dos encontros em Episódios de Ensino

\begin{tabular}{|c|c|c|c|c|}
\hline Blocos & $\begin{array}{l}1^{\text {a }} \text { Etapa: } \\
\text { Verificação de } \\
\text { conhecimentos } \\
\text { já apropriados. } \\
\text { (1) }\end{array}$ & $\begin{array}{l}2^{\text {a }} \text { Etapa: } \\
\text { Apropriação } \\
\text { das formas e } \\
\text { conteúdos } \\
\text { clássicos } \\
(2)\end{array}$ & \begin{tabular}{l}
$3^{\circ}$ Etapa: \\
Técnicas e \\
conhecimento \\
s necessários \\
à objetivação \\
do conteúdo \\
\multicolumn{1}{|c}{$(3)$}
\end{tabular} & $\begin{array}{l}4^{\text {a }} \text { Etapa: } \\
\text { Objetivação e } \\
\text { criação } \\
\text { artística } \\
\qquad 14)\end{array}$ \\
\hline $\begin{array}{c}\text { Emoções e } \\
\text { sentimentos } \\
\text { e Artes } \\
\text { (A) }\end{array}$ & $\begin{array}{l}\text { Encontro } 2 \\
\text { Encontro } 3\end{array}$ & $\begin{array}{l}\text { Encontro } 2 \\
\text { Encontro } 3 \\
\text { Encontro } 8 \\
\text { Encontro } 9 \\
\text { Encontro } 10\end{array}$ & $\begin{array}{l}\text { Não houveram } \\
\text { encontros com } \\
\text { esta temática }\end{array}$ & $\begin{array}{l}\text { Não houveram } \\
\text { encontros com } \\
\text { esta temática }\end{array}$ \\
\hline $\begin{array}{l}\text { Artes: } \\
\text { Pintura } \\
\text { (B) }\end{array}$ & Encontro 3 & $\begin{array}{l}\text { Encontro } 4 \\
\text { Encontro } 5 \\
\text { Encontro } 10\end{array}$ & $\begin{array}{l}\text { Encontro } 6 \\
\text { Encontro } 7\end{array}$ & $\begin{array}{l}\text { Encontro } 11 \\
\text { Encontro } 12\end{array}$ \\
\hline $\begin{array}{l}\text { Artes: } \\
\text { Música } \\
\text { (C) }\end{array}$ & \begin{tabular}{|l|} 
Encontro 1 \\
Encontro 13
\end{tabular} & $\begin{array}{l}\text { Encontro } 14 \\
\text { Encontro } 15 \\
\text { Encontro } 16 \\
\text { Encontro } 17\end{array}$ & $\begin{array}{l}\text { Encontro } 18 \\
\text { Encontro } 19 \\
\text { Encontro } 20 \\
\text { Encontro } 21\end{array}$ & $\begin{array}{l}\text { Encontro } 22 \\
\text { Encontro } 23 \\
\text { Encontro } 24 \\
\text { Encontro 25 }\end{array}$ \\
\hline
\end{tabular}

Desta forma, o primeiro episódio tratou do contato inicial, em situação de intervenção formativa, com as crianças e dos esclarecimentos acerca do processo de intervenção formativa do ensino de artes que iríamos desenvolver junto a elas na escola.

O segundo episódio referiu-se à verificação de conhecimentos já apropriados sobre emoções e sentimentos, artes, música, quadros, desenhos, pintores e compositores. Para averiguarmos o que conheciam acerca das músicas, utilizamos de uma brincadeira chamada "qual é a música?", na qual tocávamos o áudio de algumas músicas e as crianças deveriam adivinhar quais eram os seus títulos, ou os nomes ela do(a)(s) artista(s) que as cantavam/tocavam. Foram escolhidas canções na música popular brasileira (MPB), rock nacional, samba, música clássica, funk, músicas infantis, temas de filmes e telenovelas infantis. As crianças conheciam apenas funk, além das de trilhas sonoras de filmes e telenovelas infantis. Sobre as pinturas, elas compreendiam como arte apenas as figuras que costumavam desenhar, como por exemplo, flores, animais e seres humanos. 
O terceiro retratou a apropriação de clássicos da pintura e o contato com seus principais quadros. Ao se depararem com diferentes obras de artes e a contextualização histórica destas pinturas, as crianças passaram a ampliar seus repertórios acerca das artes e a levar a vivência de nossa pesquisa-intervenção para seu cotidiano. Por exemplo: Frida começou a perceber as pinturas ou artistas sobre quem ensinamos em comerciais de televisão e centros culturais.

O quarto episódio contou com a temática da apropriação de técnicas e conhecimentos da pintura pelos estudantes. Nele, analisamos as vivências dos sujeitos participantes da pesquisa nas atividades nas quais se apropriavam de algumas técnicas de desenho e pintura.

O quinto episódio versou sobre momentos de apropriação de conteúdos que abordem as emoções e sentimentos e Artes. Neste episódio há diálogos acerca das emoções e sentimentos suscitados pelo filme "Divertidamente", o qual assistimos com os sujeitos. As crianças responderam a perguntas sobre o que é raiva, amor, alegria, tristeza, medo, dentre outras formas de emoção.

O sexto, sobre a objetivação e criação artística da pintura, foi o episódio no qual se retrataram os momentos de criação artística e estética por meio de desenho e pintura, como pode ser observado na figura abaixo:

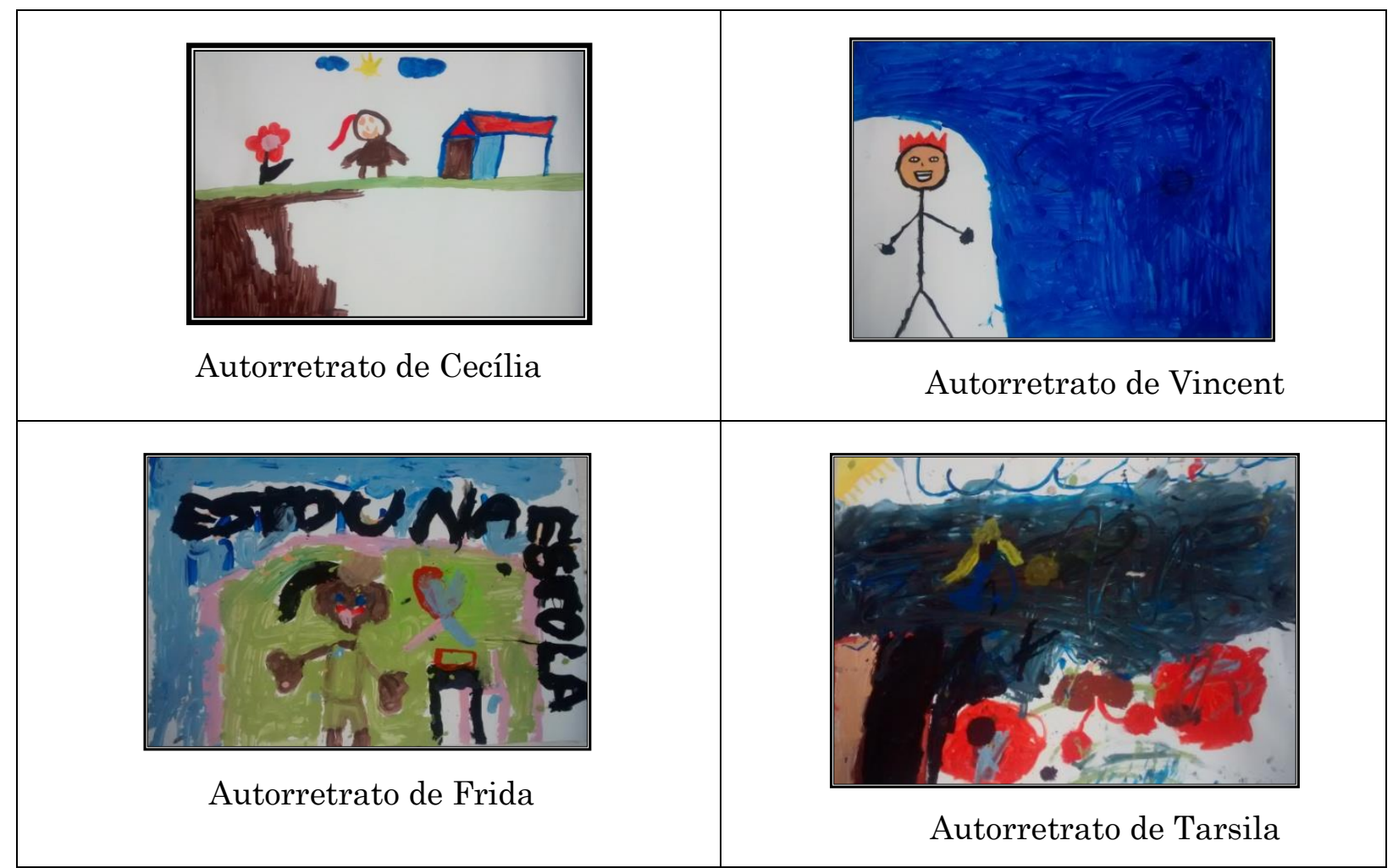




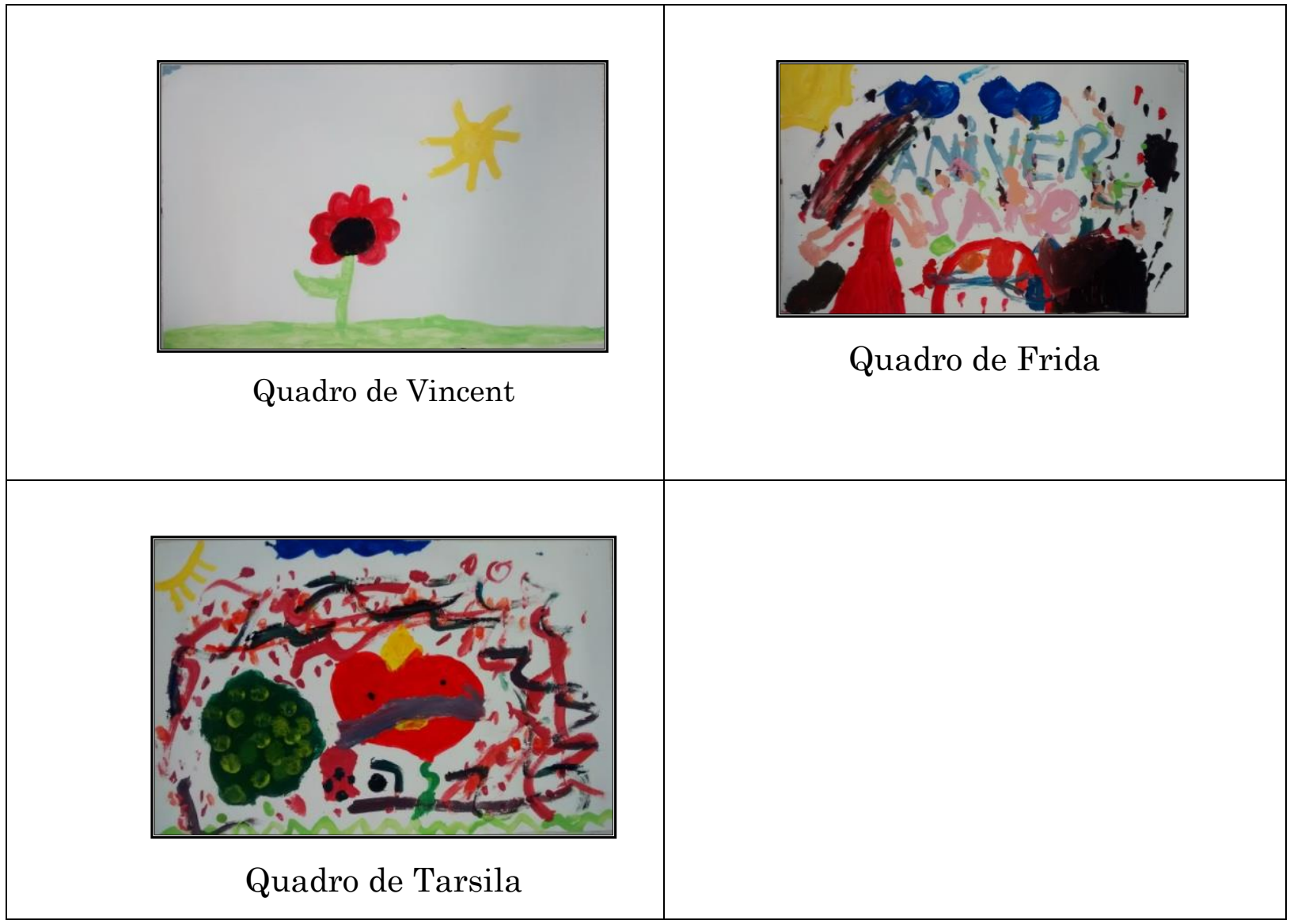

O sétimo episódio mostrou como os estudantes se apropriaram dos clássicos da música nacional e internacional, em que conheceram clássicos do rock, da MPB, do samba, do forró e da música clássica. Um dado interessante a ser mencionado é que, ao ouvir a obra "Quatro Estações" (Primavera) de Vivaldi, Frida expressou por meio de falas e gestos estar em um jardim, ouvindo o canto de pássaros, levandonos a considerar provável ela ter vivenciado emoções advindas da música de Vivaldi.

O oitavo episódio versou sobre o ensino e aprendizagem das técnicas e conhecimentos da música, onde, as crianças entraram em contato com diferentes instrumentos musicais como violão, guitarra, baixo, gaita, teclado, pandeiro, chocalho e triângulo.

O nono episódio relatou a criação artística por meio da construção coletiva de uma música sobre a realidade dos estudantes. Para a composição desta música, debatemos quais situações presentes na escola geram emoções e sentimentos tristes e alegres e, escrevemos uma paródia para a música “Telegrama” de Zeca Baleiro, com a seguinte letra: 
Eu tava triste, tristinho

Não me deixaram jogar bola na escola

Depois que eu errei o passe

Brigaram comigo,

Me empurraram, me chutaram, me xingaram

E me deixaram de lado

Fizeram bullying comigo

Por um instante achei que havia perdido todos meus amigos

Me isolei num cantinho

Fiquei com raiva, revoltado com as pessoas que me agrediram

Mas ontem eu recebi uma mensagem

Eram os amigos da escola

Me chamando pra tomar uma coca-cola

Ai eu fiquei feliz, eu fiquei feliz, eu fiquei feliz, fiquei muito, muito, muito feliz

Porque o que eu vi chegando lá me fez dar muita risada

Os meus amigos

Fizeram uma música muito engraçada

Prometeram que não iam mais me bater

E se desculparam da mancada

Mama, ô mama, ô mama, agora eu posso brincar, agora eu posso brincar

Agora eu posso, posso, posso, agora eu posso brincar

Vem meu irmão, vamos jogar futebol

"Nunca perca a amizade"

O décimo episódio analisou a conversa de avaliação final que realizamos com os estudantes sujeitos da pesquisa. Nela, reformulamos questões sobre o que pensavam ser emoções e sentimentos, sua compreensão das artes, bem como relembramos dos principais momentos de nossa intervenção. O décimo episódio traz elementos avaliativos de todo o processo interventivo formativo, pois nele analisamos quais foram as principais vivências das crianças ao longo de todo o processo de pesquisa, bem como, suas novas apropriações artísticas e compreensões acerca das artes.

Ao longo de todos os dez episódios, notamos que as crianças, principalmente Frida e Vincent, mostraram um grande envolvimento com o processo de ensino das artes. Frida, inclusive, começou a participar de aulas de violão extraclasse e Vincent mudou algumas de suas concepções éticas e morais sobre trabalho e escravidão, conforme identificamos por meio das discussões advindas de quadros como Os Operários de Tarsila do Amaral e Café de Candido Portinari. 
O processo de intervenção, portanto, enfatizando o ensino das artes numa perspectiva humanizadora, na qual se criaram condições educativas favoráveis ao processo de desenvolvimento dos sujeitos, segundo nossa avaliação, efetivou-se satisfatoriamente na escola pois possibilitou o acesso, apropriação, fruição, debates, conversas e ensino diversificado de conteúdos relacionados às obras de arte vivenciadas, sendo que o trabalho educativo escolar foi essencial para esse processo.

\section{Algumas considerações finais}

Não podemos atribuir as transformações observadas nos sujeitos, no decorrer da pesquisa-intervenção apenas ao nosso trabalho. Mas, ainda assim, identificamos que os seis meses de atividade puderam proporcionar apropriações e objetivações diferenciadas, assim como vivências artísticas significativas para os sujeitos.

Segundo nossa avaliação no interior do GEIPEEthc, os encontros de intervenção possibilitaram ensino de qualidade e aprendizagem significativa dos sujeitos, além de situações que contribuíram para as crianças compreenderem histórica e esteticamente algumas das emoções e sentimentos humanos vivenciados ao longo do processo. Concluímos, pois, que foram criadas situações para que os sujeitos compreendessem melhor a esfera afetiva de suas vidas tanto na escola como também junto aos seus amigos e em família.

Portanto, em acordo com a teoria histórico-cultural e pedagogia históricocrítica, ambas teorias baseadas no materialismo histórico dialético, defendemos que a organização e efetivação do processo de ensino intencional, por meio das artes na escola, podem garantir aos estudantes se apropriarem dos significados sociais das emoções e sentimentos humanos presentes nas obras de arte, de forma a generalizar tais funções em suas próprias vivências tanto na escola como fora dela, desenvolvendo-se cognitiva e afetivamente em uma direção humano-genérica.

Para finalizar, precisamos enfatizar o papel do professor nesse processo humanizador, pois sem a realização de um trabalho educativo intencionalmente planejado e organizado na sua forma e conteúdo, o ato de educar na escola torna- 
se mera reprodução, mero arremedo, negando, assim a função ontológica do trabalho educativo, que é criar condições favoráveis para a humanização dos estudantes por meio da socialização dos bens culturais mais desenvolvidos já construídos pela humanidade, dentre eles, as obras de arte clássicas, dentre outros objetos culturais humano-genéricos.

\section{Referências}

DAVIDOV, V. V. La enseñanza escolar y el desarrollo psíquico. Moscú: Editorial Progreso, 1988.

DUARTE, N. Arte e formação humana em Vigotski e Lukács. In: DUARTE, N.; FONTE, S. S. de Arte, Conhecimento e Paixão na formação humana. Campinas: Autores Associados, 2010, p.145-163.

FELIX, T.S.P. A timidez na escola: um estudo histórico-cultural. 2013. 158 f. Dissertação (Mestrado em Educação) Faculdade de Ciências e Tecnologia, Universidade Estadual Paulista, Presidente Prudente, 2013.

FELIX, T. S. P. O desenvolvimento das emoções e sentimentos da criança na construção de sua personalidade: as atividades artísticas como mediadoras desse processo na escola. 2018. 246 f. Tese (Doutorado em Educação) Faculdade de Ciências e Tecnologia, Universidade Estadual Paulista, Presidente Prudente, 2018.

LUKÁCS, G. Introdução a uma estética marxista. Rio de Janeiro: Civilização Brasileira, 2a. Ed., 1978.

MARTINS, L. M. O desenvolvimento do psiquismo e a educação escolar: contribuições à luz da psicologia histórico cultural e da pedagogia histórico-crítica. 2011. 250 f. Tese (Livre docência em Psicologia da Educação) Departamento de Psicologia da Faculdade de Ciências da Universidade Estadual Paulista, Bauru, 2011.

Campinas: Autores Associados, 2013.

O desenvolvimento do Psiquismo e a Educação Escolar.

NASCIMENTO, C. P. A organização de pesquisas em psicologia e educação na teoria histórico-cultural: o ensino e a formação do pensamento teórico. In: ASSOCIAÇÃO BRASILEIRA DE PSICOLOGIA ESCOLAR E EDUCACIONAL. CONPE-Anais. Maringá, 2011.

NASCIMENTO, C. P. A atividade pedagógica da Educação Física: a proposição dos objetos de ensino e o desenvolvimento das atividades da cultura corporal. 2014. 293 
p. Tese (Doutorado) - Faculdade de Educação, Universidade de São Paulo, São Paulo, 2014.

SAVIANI, D. Pedagogia histórico-crítica: primeiras aproximações. Campinas, SP: Autores Associados, 2011.

TOASSA, G. Emoções e vivências em Vigotski: investigação para uma perspectiva histórico-cultural. Tese (Doutorado) - Instituto de Psicologia, Universidade de São Paulo, São Paulo, 2009.

VIGOTSKI, L. S. Obras escogidas (Psicología infantil). Madrid: Visor Distribuiciones, 1930-1934/1996. iv. Psicologia da arte. São Paulo: Martins Fontes, 1925/2001. Teoria de las emociones: estudio histórico-psicológico. Madrid:

Akal, 1933/2004.

- El Desarrolo de Los Procesos Psicológicos Superiores.

Barcelona, Crítica, 1931/2006.

VIGOTSKI, L. S. A construção do pensamento e da linguagem. São Paulo: Martins Fontes, 1934/2009a.

1930/2009b.

A Imaginação e a Arte na Infância. Lisboa: Relógio D’Água,

VIOTTO FILHO, I.A.T. Processo grupal e construção coletiva do conhecimento: a história do GEIPEEthc. In: VIOTTO FILHO, et. al. Processo grupal e práxis científica educativa. São Carlos, SP: Pedro \& João, 2018. 